\title{
IV. „Von der Not der Juden und der Not des Judentums“ - Antisemitismus in Deutschland und Polen in den dreißiger Jahren
}

\author{
1. Eine „ansteckende Krankheit“: \\ Der NS-Antisemitismus und Osteuropa
}

Anfang 1936 erhielt das Büro Alfred Rosenbergs, des Ideologen der NSDAP, ein von einer "treuen“ Deutschen verfaßtes Schreiben über ihre Erlebnisse auf einer Reise nach Lodz, der Geburtsstadt der Verfasserin. Darin hieß es unter anderem:

„... Kaum hatten wir die Grenze Drachenberg-Rawicz hinter uns, erlebten wir auch schon etwas und zwar mit einem Juden, welcher aus Deutschland kam, nach Warschau fahren wollte und in Posen in (unseren) Zug stieg. Er tat ganz erschöpft, und erzählte mit leiser und matter Stimme, wie man ihn in Deutschland geschlagen und getreten hätte, er sei am ganzen Körper grün und blau. Wir waren sprachlos, da sprang aber mein junger Schweizer Begleiter auf, verbat sich ganz energisch diese Märchen und sagte, es sei doch merkwürdig, daß man immer diese Greuelnachrichten erst jenseits der Grenze höre und in Deutschland davon nichts sehe, denn wir kämen auch aus Deutschland. Darauf schwieg der Jude, saß eine Zeitlang still in seiner Ecke und entfernte sich dann. Wir ärgerten uns, daß wir so voreilig die Erzählung des Juden unterbrachen, ohne nach seinen Personalien zu fragen, denn er hatte, wie er angab, Verwandte in Berlin. Als der Jude nach einiger Zeit zurückkam, wollten wir das Versäumnis nachholen, um in Deutschland davon Meldung zu machen. Mein junger Begleiter bat den Juden ganz freundlich, uns doch noch etwas von seinen Erlebnissen zu erzählen, da kam er aber schön an! ,Er wollte überhaupt nicht mehr von Politik reden!', schrie er, wir seien Deutsche und blieben Deutsche und er, der Jude sei ein Pole und bleibe ein Pole. Er schrie es zweimal, so laut, daß ich dachte, jetzt gibt es einen Mordskrach und uns ergeht es schlecht. Es war unser Glück, daß wir einem Polen, der während des Juden Abwesenheit noch in (unseren) Wagen kam, von der Sache erzählten und ihm auch sagten, daß alles Lug und Trug ist, was der Jude vorbrachte. Wir sagten dem Polen, wie vorbildlich und schön es jetzt in Deutschland sei, wie wir stolz sein könnten auf unser Deutschland und auf den Mann, der jetzt Deutschlands Geschicke in den Händen hat. Auch erzählten wir von der großen Liebe unseres Volkes zum Kanzler. Dieser Pole legte sich gleich ins Mittel und hat den Juden mit seinem Koffer einfach aus unserem Abteil herausgejagt und ihm mit einer Anzeige gedroht. Dann vertraute uns der Pole an, daß er im Herzen auch ein Hitlerfreund sei, obgleich er Pole sei, aber was Recht ist müsse Recht bleiben. Auch bemerkte er, daß nur ganz wenige seine wahre Gesinnung kennen, denn man müsse damit in Polen sehr vorsichtig sein ..."1

Dieser Brief wirft Licht auf spezifische Merkmale des deutschen und polnischen Antisemitismus. Wir dürfen davon ausgehen, daß der jüdische Reisende in Deutschland tatsächlich von Angehörigen der SS oder SA geschlagen worden war und nun nach Polen zurückkehren wollte. Dokumente der diplomatischen Vertretungen Polens in Deutschland, die sich heute im polnischen Staatsarchiv in Warschau befinden, berichten über Hunderte von Vorfällen, in denen Juden osteuropäischer Her-

1 BAP, Dienststellen Rosenberg Nr. 1132/3846, Bericht über meinen Besuch in meiner Geburtsstadt Lodz, 26. 1. 1934, 62 Di 1. 
kunft 1933 von deutschen Sicherheitsbeamten körperlich mißhandelt wurden. Die deutsche Reisende schenkte den Worten des mitreisenden Juden keinen Glauben, ja sah darin vielmehr eine Art Hetze gegen Deutschland. Diese Ungläubigkeit resultierte nicht nur aus einer wirklichen oder vorgeblichen Naivität. Angriffe auf Juden, insbesondere die körperlichen Mißhandlungen, erfolgten in der Regel nicht in der Öffentlichkeit, sondern im Verborgenen, in den Gaststätten der SS und den Kellern der Polizei. Loyalität und Hingabe an das Regime veranlaßten die Reisende, später Bericht zu erstatten, und bewogen sie zu dem Versuch, die Personalien des jüdischen Reisenden zu ermitteln, um ihn bei den Behörden denunzieren zu können. Der polnische Reisende dagegen hat zweifellos mit der politischen Rechten sympathisiert und die antisemitischen Anschauungen dieses Lagers unterstützt. Die Gewalt, mit der er gegen den jüdischen Reisenden vorging, war in Polen nicht selten, wo sich der Antisemitismus direkter und aggressiver manifestierte als zunächst in Deutschland. Seine Sympathie mit dem Dritten Reich, so der Pole, könne er nicht öffentlich zum Ausdruck bringen. Auch dies war für die Situation in Polen Anfang 1934 typisch, als dort die Ablehnung Deutschlands noch stärker war als antisemitische Tendenzen, mit denen das neue Regime in Deutschland assoziiert wurde.

Mitte der dreißiger Jahre kam es insbesondere infolge des Todes von Jozef Pilsudski zu einer starken Zunahme des Antisemitismus in Polen. Die wirtschaftliche Depression und der Übergang von einer demokratischen Regierung zu einem autoritären System förderten derartige Tendenzen. In dieser Hinsicht entsprach die Lage in Polen der Situation in anderen osteuropäischen Ländern, in denen es in den Jahren vor dem Zweiten Weltkrieg vor dem Hintergrund der wirtschaftlichen Krisen und dem Aufstieg der Nationalsozialisten zu heftigen Auseinandersetzungen zwischen politisch gemäßigten Kräften und der extremen nationalistischen Rechten $\mathrm{kam}^{2}$. Zu diesen internen Ursachen gesellte sich ein entscheidender externer Aspekt - der Einfluß der politischen Entwicklungen in Deutschland auf Osteuropa. Auch in Polen entwickelte sich der Antisemitismus unter dem Einfluß der antisemitischen Strömungen in den Nachbarländern. Seit den dreißiger Jahren des 19. Jahrhunderts wurde unter dem Einfluß der antijüdischen bzw. antisemitischen Atmosphäre in Deutschland und Rußland in der polnischen Presse und Literatur die Forderung nach bürgerlicher Gleichberechtigung der Juden hart angefochten ${ }^{3}$. Der Erste Weltkrieg verstärkte dann zusätzlich die Spannungen zwischen Juden und Polen in den polnischen Gebieten. Im Laufe des Krieges wurde die jüdische Bevölkerung einer deutschfreundlichen Gesinnung verdächtigt. Sie geriet in direkten Konflikt mit der einheimischen polnischen Bevölkerung und so in die Isolation - Tendenzen, die während der Zeit der Weimarer Republik angesichts weiterbestehender territorialer Konflikte zwischen Deutschland und Polen ihre Fortsetzung fanden.

Die Machtübernahme Adolf Hitlers und die Stabilisierung des nationalsozialistischen Deutschlands leiteten eine neue Phase der wechselsseitigen Beeinflussung des Antisemitismus in Polen und Deutschland ein. Das nationalsozialistische Deutschland hatte sich die Verdrängung der jüdischen Bevölkerung aus Wirtschaft und Gesellschaft zum Ziel gesetzt. Für viele Polen hatte diese Politik Vorbildcharakter. Gleichzeitig jedoch wurde das Erstarken Deutschlands als eine Bedrohung der pol-

2 Mendelsohn, East Central Europe, S. 68.

3 Korzec, Antisemitism, S. 20 f. 
nischen Unabhängigkeit verstanden, die nicht übersehen oder vernachlässigt werden durfte. Ob man Deutschland nun mit Sympathie oder Antipathie begegnete, in jedem Fall fanden Regierung und Opposition in Polen durch die Auseinandersetzung mit Deutschland und dem deutschen Antisemitismus zu ihren Positionen gegenüber den einheimischen Juden; der deutsche Antisemitismus hatte starken Einfluß auf die rechten Kreise in Polen und die polnische Regierung und war auch ein steter Faktor in den diplomatischen Beziehungen zwischen Polen und Deutschland.

1928 hatte sich die polnische Rechte als Nationale Partei-Stronnictwo Narodwe - organisiert. Im Zentrum der rechten Szene stand der vom Geiste des rechten Führers Roman Dmowski geprägte Endecja-Block ${ }^{4} .1934$ spaltete sich vom rechten Lager die Organisation Oboz Narodowo-Radykalny, also das ,national-radikale Lager", ab, das unter der Abkürzung ONR bekannt werden sollte. Diese Organisation orientierte sich ausdrücklich nach dem Modell der Nationalsozialisten und vertrat eine rassistische Weltanschauung in Verbindung mit einem radikalen gesellschaftspolitischen Programm. Kurze Zeit nach seiner Gründung wurde der ONR bereits zu einer verfassungswidrigen Organisation erklärt ${ }^{5}$. Somit blieb die Endecja die einzige extreme Gruppierung der politischen Rechten innerhalb des gesetzlichen Rahmens. Ihre nationalistischen, rassistischen Anschauungen waren jedoch nur wenig gemäßigter als die des $O N R$.

Das Verhältnis der Endecja zu Deutschland war von Anfang an gespannt. In der Vergangenheit hatte Dmowski Deutschland zum Feindbild Nummer eins für den polnischen Nationalismus erklärt, Preußen und das preußische Modell jedoch als nachahmenswert empfohlen ${ }^{6}$. Das nationalsozialistische Deutschland stellte die polnische Rechte vor eine ähnliche Herausforderung: einerseits waren die Machtzunahme Deutschlands und das Anwachsen des deutschen Nationalismus eine fortwährende Bedrohung Polens (es konnte kein Zweifel darüber bestehen, daß ein erstarktes Deutschland die infolge der Niederlage im Ersten Weltkrieg und des Versailler Vertrags verlorenen Gebiete zurückfordern werde); andererseits bot die antisemitische Politik Deutschlands ein nachahmenswertes, erfolgreiches Modell für den polnischen Antisemitismus ${ }^{7}$. Die Endecja zeigte Verständnis und Begeisterung für das „nationale Erwachen“ Deutschlands und stimmte der damit einhergehenden "Lösung der Judenfrage“ in Deutschland durch Aufhebung der politischen Gleichberechtigung von Juden und deren Ausweisung zu. Aber auch in diesem Zusammenhang mußte sich die Endecja mit widersprüchlichen Bestrebungen auseinandersetzen: Juden, die aus Deutschland ausgewiesen wurden oder Deutschland infolge der nationalsozialistischen Machtübernahme verließen, kehrten nach Polen zurück. Damit konnte sich die Endecja nicht einverstanden erklären. Sie forderte, die polnische Regierung dürfe weder polnische Juden in Deutschland unterstützen noch jüdischen Emigranten die Rückkehr nach Polen gestatten ${ }^{8}$. Diese Juden, so argumentierte die Endecja, versuchten, Polen in fremde Konflikte zu verwickeln und die Beziehungen zwischen Deutschland und Polen zu stören. Der Endecja-Block ver-

4 Grünberg, National-Democratic Press.

5 Korzec, Antisemitism, S. 81 f.; Mendelsohn, East Central Europe, S. 70.

6 Gutman, Polish Antisemitism, S. 98.

$7 \mathrm{Zu}$ der Relation von Furcht und Bewunderung siehe: Teeni, Hitler's Rise, S. 56f.; Grünberg, National-Democratic Press, S. 108; Gutman, Polish Antisemitism, S. 106.

8 Grünberg, National-Democratic Press, S. $106 f$. 
folgte wachen Auges die antisemitische Politik Deutschlands, seine Zeitungen berichteten detailliert über die Ereignisse im Nachbarland'. Das wesentliche Interesse der Endecja richtete sich jedoch auf den praktischen Erfolg der deutschen Politik also auf die Verdrängung der Juden -, weniger auf das ideologische Element ${ }^{10}$. Gleichzeitig begrüßte sie die antisemitischen Maßnahmen Deutschlands als Elemente eines Kampfes zwischen zwei dem polnischen Staate feindlich gesonnenen Mächten ${ }^{11}$.

Der wesentliche Erfolg des rechten Lagers bestand letztlich darin, daß es ihm gelang, „die Judenfrage“ zum zentralen Thema im öffentlichen Diskurs Polens in den dreißiger Jahren zu machen. Das Lager Jozef Pilsudskis, die Sanacja, hatte in der Vergangenheit keine auffallenden antisemitischen Tendenzen gezeigt. Seine Mitglieder hatten sich von der antisemitischen Begeisterung, die die polnische Rechte ergriffen hatte, nicht anstecken lassen, auch wenn sich in den Äußerungen einzelner manche antisemitische Botschaft versteckte ${ }^{12}$. Potentielle Antisemiten in Pilsudskis Lager wurden aber durch die Persönlichkeit des Marschalls gemäßigt und gezügelt $^{13}$. Nach Pilsudskis Tod fehlte es den polnischen Regierungskreisen an einer charismatischen Persönlichkeit, die die Welle des Antisemitismus hätte aufhalten können. Durch ihre Propaganda gelang es der rechten Szene, breite Schichten der polnischen Öffentlichkeit von der Annahme zu überzeugen, die Existenz der jüdischen Minderheit sei der eigentliche Grund für die Probleme der polnischen Bevölkerung. Die Endecja konnte mit diesem Argument weite Bevölkerungskreise auf ihre Seite ziehen und die polnische Regierung zwingen, den Forderungen der Antisemiten nachzukommen. Die Regierung ihrerseits befand sich in einem Dilemma: Sollte sie die Meinung der Weltöffentlichkeit achten und der Verpflichtung gegenüber Minderheiten im eigenen Land nachkommen, oder die eigene Position in Polen stabilisieren, indem sie das polnisch-ethnische Element akzentuiert bevorzugte? Unter den gegebenen Umständen entschloß sich die Sanacja zu eigenen antijüdischen Ausfällen. In diesen Zusammenhang fiel die Initiative zum Verbot des koscheren Schlachtens, eine Angelegenheit, die die traditionelle Judenfeindschaft mit partikularen Wirtschaftsinteressen verband. Auch wenn die Sanacja nicht zum Vorreiter im Kampfe gegen Juden wurde, so wollte sie doch ihre Popularität in Polen nicht deswegen verlieren, weil sie für die Bewahrung des Status der jüdischen Bevölkerung eintrat ${ }^{14}$. Praktisch schlug die polnische Regierung eine Politik ein, die auf die Verdrängung von Juden aus Polen abzielte, wenn sie öffentlich wirtschaftlichen Boykott und Repressionen gegen Juden in Polen als kurzfristige Maßnahmen

${ }^{9}$ Melzer, Relations, S. 200-203.

10 Grünberg, National-Democratic Press, S. 109.

11 Melzer, Relations, S. 200.

12 Korzec, Antisemitism, S. 82.

13 Zum Antisemitismus in der Regierungszeit Pilsudskis siehe: Mendelsohn, East Central Europe, S. 69.

14 Als eine Delegation polnischer Juden beim Leiter der Abteilung für Völkerfragen im polnischen Außenministerium, Sukienik, vorsprach und ihn bat, gegen die Aufrufe zu Pogromen vorzugehen, antwortete Sukienik: „In diesen Tagen ist jeder in Polen ein Antisemit. Wir können die Polizei nicht einsetzen, um jeden Juden einzeln zu schützen." Korzec, Antisemitism, S. 90. 
unterstützte und sich auf die Auswanderung als einzige langfristige „Lösung der Judenfrage" in Polen konzentrierte ${ }^{15}$.

Mit der Gründung einer neuen Regierungspartei Anfang 1937 unter dem Namen Obóz Zjednoczenia Narodowego (OZN - Lager der Nationalen Einheit) und der Kooperation zwischen dieser Partei und extremen Rechtsparteien war der Antisemitismus endgültig in die Regierungskreise Polens gelangt ${ }^{16}$. Der OZN nahm eine offen antisemitische Position ein und lehnte jegliche Integration von Juden in Polen ab. In den Jahren 1938-1939 strebte er sogar die Aufhebung der Staatsbürgerschaft von polnischen Juden an. Im Hinblick auf die Frage des Status der Juden unterschieden sich Regierung und Opposition nicht in ihren Zielen und grundsätzlichen Positionen. Unterschiedliche Akzente gab es allein hinsichtlich der praktischen Durchführung ${ }^{17}$.

Die Position der polnischen Regierung gegenüber der jüdischen Minderheit hing unmittelbar mit den Beziehungen Polens zu Deutschland zusammen. Die polnische Regierung verfolgte einen äußerst vorsichtigen Kurs gegenüber dem erstarkenden Nachbarn. Polen und Deutschland hatten sich 1919 im Rahmen eines umfassenden Vertrages zum Schutze der jeweiligen Minderheiten im eigenen Land verpflichtet. Dieser Vertrag wurde später durch Zusatzverträge - zwischen Polen und Danzig am 9. November 1920 und Polen und Deutschland am 15. Mai 1922 (sogenannter Oberschlesienvertrag) - zum Schutze der Minderheiten im jeweiligen Staatsgebiet ergänzt ${ }^{18}$. Am 26. Januar 1934 unterzeichneten beide Staaten einen Nichtangriffspakt, der zehn Jahre gelten sollte. Doch bereits am 13. September 1934 erklärte der polnische Außenminister Jozef Beck, Polen sei der Verpflichtungen aus dem Vertrag zum Schutze der Minderheiten enthoben. Fortan zog Polen bilaterale Verträge und Übereinkommen internationalen Verträgen vor. Durch diese Haltung wurde letztlich die Autorität des Völkerbundes und des Versailler Vertrags beeinträchtigt, ein Schritt, der die deutsche Position nicht unwesentlich stärkte ${ }^{19}$.

Der Schutz der Minderheiten stand im Mittelpunkt der Beziehungen zwischen Deutschland und Polen und bestimmte den Grad der innenpolitischen Diskriminierungen der ethnischen Minoritäten. Auf der Basis des Minderheitenvertrags konnten Juden die Einführung antijüdischer deutscher Gesetze in Oberschlesien und Danzig bis zum Ende der Vertragsgültigkeit 1937 verhindern ${ }^{20}$. Generell kam es allerdings zu einem Ungleichgewicht zwischen der Bedeutung der deutschen Minderheit für die deutsche Außenpolitik gegenüber einer - nach Ansicht der polnischen Regierungsbehörden - zu verzeichnenden Vernachlässigung der polnischen Minderheit. Der Versuch Polens, sich der internationalen Vereinbarung zum Minderheitenschutz $\mathrm{zu}$ entziehen, war für diese Unstimmigkeit ein deutlicher Ausdruck; Deutschland hielt demgegenüber zunächst an seinen Verpflichtungen fest ${ }^{21}$.

15 Mendelsohn, East Central Europe, S. 71.

16 Melzer, Relations, S. 209; Korzec, Antisemitism, S. 93, 97 f.

17 Mendelsohn, East Central Europe, S. 72.

18 Stillschweig, Minderheitenverträgen, S. 38, $94 \mathrm{ff} ., 199 \mathrm{ff}$.

19 Korzec, Antisemitism, S. 81.

20 Zur Bernheim-Petition, die zum Gipfel des Völkerbundes über die Rechte von Juden in Oberschlesien und Danzig führte, siehe: Feinberg, Bernheim-Petition.

21 Akten zur deutschen Auswärtigen Politik (Band III), 9190/E 646 479-81, Der Konsul in Genf, Krauel, an das Auswärtige Amt am 7. 9. 1934, S. $380 \mathrm{ff}$. 
Auch die deutsche Außenpolitik befand sich hier in einem Dilemma: Einerseits war der Schutz der Minderheiten im Rahmen internationaler Abkommen erzielt worden, auf deren Einhaltung Deutschland bestehen wollte; andererseits war Deutschland selbst aus dem Völkerbund ausgetreten, hatte also die Körperschaft verlassen, die die Einhaltung dieser Verträge völkerrechtlich garantierte ${ }^{22}$. Daher waren Deutschlands Möglichkeiten, Polen hinsichtlich der Einhaltung seiner Verpflichtungen zu beeinflussen, begrenzt, und es versuchte im internationalen Rahmen den Umstand zu verbergen, daß es sich um einen polnisch-deutschen Konflikt handelte: Deutschland bemühte sich, das prinzipielle Element der Haltung gegenüber Minderheiten zu betonen. Die andere Seite der Medaille des Minderheitenschutzes war jedoch die Instrumentalisierung dieser Minderheit durch das NS-Regime ${ }^{23}$. Praktisch benutzte das NS-Regime die Deutschen in Polen als fünfte Kolonne, die die Fundamente der polnischen Regierung untergraben und den Antisemitismus in Polen durchsetzen sollte. Die deutsche Minderheit ließ sich von der deutschen Propaganda nur allzu leicht instrumentalisieren. Angehörige dieser Gruppe lebten nicht im Reichsgebiet und brauchten daher den „unangenehmen Seiten“ des Nationalsozialismus nicht in die Augen zu schauen. Zudem waren sie für den Rückhalt und Schutz, den das Reich ihnen gewährte, dankbar ${ }^{24}$. In der deutschsprachigen Presse Polens war eine ungehemmte, verleumderische antisemitische Propaganda, die sich aus nationalsozialistischen Presseverlautbarungen speiste, weit verbreitet. Gleichzeitig gelangten Tausende von antisemitischen Broschüren in polnischer Sprache in die Wirtschaftskreise Polens ${ }^{25}$. Praktisch agierte die deutsche Minderheit in Polen mit äußerster Vorsicht, da sie davon ausging, daß sich der Antisemitismus in Polen angesichts der dort herrschenden Zustände auch ohne Manipulationen entwickeln werde. Die polnische Regierung, die sich auf die Zerstörung des jüdischen Wirtschaftssektors konzentrierte, hatte keinen Freiraum, sich mit dem wirtschaftlichen Erstarken der deutschen Minderheit im Westen Polens auseinanderzusetzen. Sie formulierte auch keine konsequente politische Linie gegenüber der deutschen Bevölkerung in Polen, während die jüdische Minderheit eine gewisse Indifferenz im Hinblick auf die Entwicklungen in den Reihen der deutschen Bevölkerung zeigte und nicht in der Lage war, vor den Gefahren zu warnen, die von der destruktiven Tätigkeit dieser Minderheit ausgingen ${ }^{26}$.

Mit dem Nichtangriffspakt, den Deutschland und Polen 1934 unterzeichneten, trat für die polnischen Juden gewiß eine Wende zum Schlechteren ein. Teile der jüdischen Presse wiesen warnend auf den Zusammenhang hin zwischen einer prodeutschen Politik Polens und einer Zunahme des Antisemitismus der Regierung27. Moshe Kleinbaum (Sneh), zionistischer Politiker und Begründer der Partei der All-

22 Akten zur deutschen Auswärtigen Politik (Band III), 9190/E 646 487-91, Der Staatssekretär des Auswärtigen Amtes, von Bülow, an die Botschaften in London, Paris, Rom und Moskau und die Gesandtschaft in Warschau am 15. 9. 1934, S. $401 \mathrm{ff}$.

${ }^{23} \mathrm{Zu}$ den verschiedenen Phasen der Nazifizierung der deutschen Minderheit in Polen siche: Melzer, Minorities, S. $71 \mathrm{ff}$.

24 Mendelsohn, Minorities, S. LXf.

25 Melzer, Relations, S. $197 \mathrm{f}$.

${ }^{26}$ Korcez meint, die Feindseligkeiten zwischen polnischen Juden und Angehörigen der deutschen und ukrainischen Minderheiten begannen sogleich nach den politischen Veränderungen in Deutschland: Korzec, Antisemitism, S. 80.

27 Melzer, Relations, S. $201 \mathrm{f}$. 
gemeinen Zionisten, meinte zu diesem Zeitpunkt, der Antisemitismus trage dazu bei, Berührungsängste und Feindseligkeit zwischen Deutschland und Polen abzubauen. Die jüdische Öffentlichkeit, so Kleinbaum, zeige jedoch eine gewisse Gleichgültigkeit gegenüber dem Einfluß des deutschen Antisemitismus auf den polnischen, insbesondere im Kontext des Nichtangriffspaktes ${ }^{28}$. Dieser trage den deutschen Antisemitismus in polnische Regierungskreise, während die Verbreitung des Antisemitismus in Polen Befürchtungen der deutschen Regierung gegenüber Polen vermindere ${ }^{29}$. Der Nichtangriffspakt fand 1935 seine Fortsetzung in der Unterzeichnung eines allgemeinen Abkommens, worin sich Polen verpflichtete, antideutsche Aktivitäten in seinem Gebiet einzuschränken. Dieses Abkommen beeinträchtigte indirekt den gegen Deutschland gerichteten jüdischen Boykott in Polen ${ }^{30}$.

In den Jahren 1935 und 1936 arbeitete die polnische Regierung intensiv darauf hin, die Aufmerksamkeit und Sympathie der internationalen Öffentlichkeit für die demographischen Probleme Polens zu erringen. Die Regierung versuchte auf diesem Wege, die internationale Anerkennung der Emigration und insbesondere der Auswanderung von Juden als Lösung dieser Probleme zu gewinnen. Im Zuge dessen erweiterte Polen seine Tätigkeit im Völkerbund. Darüber hinaus konsultierte der polnische Außenminister Beck Politiker in England, Frankreich und den Vereinigten Staaten ${ }^{31}$. In jenem Jahr bekämpfte die polnische Regierung den Antisemitismus so gut wie gar nicht. Allerdings versuchte sie, ihre indirekte Beteiligung an diesen Entwicklungen zu verschleiern. 1937 kam es zu einer starken Zunahme des Antisemitismus, der verstärkt in polnischen Regierungskreisen salonfähig wurde. Die Gründung des OZN trug zu diesen Entwicklungen wesentlich bei. Es war das Jahr, in dem der Minderheitenvertrag zwischen Polen und Deutschland auslief: Ein neuer Minderheitenvertrag, der am 5. November 1937 von beiden Staaten unterzeichnet wurde, bot den Juden keine Garantien für ihren Status mehr, sondern bezog sich ausschließlich auf die deutschen und polnischen Minderheiten ${ }^{32}$. Polen war nun nicht mehr darum bemüht, die Rechte der Juden in Oberschlesien und Danzig zu schützen. Sie waren fortan Opfer der üblichen NS-Politik, die seit 1933 in allen Gebieten Deutschlands eingeführt worden war.

Die polnisch-jüdische Presse berichtete in aller Ausführlichkeit über die Entwicklungen in Deutschland und warnte ununterbrochen vor deren Einfluß auf den Antisemitismus in Polen. Einem Bericht des deutschen Botschafters in Warschau, Hans Adolf von Moltke, zufolge äußerte Außenminister Beck 1934 die Absicht, das „jüdische Element" in der polnischen Presse einzuschränken, das seiner Meinung nach für die antideutsche Haltung der polnischen Öffentlichkeit verantwortlich

28 Haynt, „Der Antisemitismus in Polen wächst“, 16. 5. 1934, bei: Sneh, Writings, S. 164 ff.

29 Melzer, Relations, S. 202; Mendelsohn, East Central Europe, S. 70.

30 Melzer, Relations, S. 203. Dazu weitere Einzelheiten im sechsten Abschnitt dieser Darstellung zum Transferabkommen und der Boykottbewegung.

31 Lipski, Diplomat in Berlin, S. $411 \mathrm{f}$.

32 Akten zur deutschen Auswärtigen Politik, (Band III), 5810/E 423 732-33, Deutscher Entwurf einer deutsch-polnischen Minderheiten Erklärung, Juni 1937, S. 925 f., 1729/H 408 408, Der Botschafter in Warschau, von Moltke, an das Auswärtige Amt am 24.6. 1937, S. 933. Akten zur deutschen Auswärtigen Politik, (Band VI), 1661/393568-572, Deutsch-polnische Minderheitenerklärung am 5. 11. 1937, S. 21 f. 
$\mathrm{war}^{33}$. In jenem Jahr ging die polnische Regierung allerdings noch nicht aktiv gegen die jüdische Presse vor. Doch die Position der polnischen Regierung gegenüber Juden wurde feindseliger, was schließlich dazu führte, daß es die polnischen Regierungsbehörden 1938 für angebracht hielten, über die jüdische Presse, die die antisemitische Politik Deutschlands hart angriff, eine Zensur zu verhängen ${ }^{34}$. Die polnische Außenpolitik war zu jenem Zeitpunkt klar auf eine prodeutsche Linie festgelegt. Kurzfristige Erwägungen um das Memelland veranlaßten Polen zu einer Unterstützung Deutschlands im Kampf gegen Litauen sowie im Konflikt mit der Tschechoslowakei35.

Unmittelbar vor Ausbruch des Zweiten Weltkrieges verbesserte sich aber die Beziehung der polnischen Bevölkerungsmehrheit zur jüdischen Minderheit ${ }^{36}$. Mit der einseitigen Aufhebung des deutsch-polnischen Nichtangriffspakts durch Deutschland am 28. April 1939 wurde Polen zum primären Ziel der deutschen Aggressionspolitik. Angesichts dieses Ereignisses verloren die rechten, prodeutsch orientierten Kräfte in Polen zunehmend an Einfluß. Polen versuchte, seine Beziehungen zu westlichen Staaten wie England und Frankreich zu verbessern, und mußte daher die jüdische Minderheit in seinem Gebiet stärker berücksichtigen. Gleichzeitig erschwerten die polnischen Regierungsbehörden der deutschen Minderheit das Leben $^{37}$. Aus jüdischer Perspektive waren dies günstige Entwicklungen, die jedoch die jüdische Bevölkerung Polens finanziell und materiell in den sich anbahnenden Konflikt Polens mit seinem Nachbarland einspannten. Der Krieg und die Ereignisse in seiner Folge setzten der kurzfristigen Annäherung zwischen polnischer und jüdischer Bevölkerung in Polen ein rasches Ende.

Antisemitische Maßnahmen in Polen während der dreißiger Jahre sollten also stets im Lichte der deutsch-polnischen Beziehungen gesehen werden. Bestimmte antisemitische Tendenzen hatten zwar eine lange Tradition in Polen selbst, doch sie wurden angesichts der Entwicklungen antisemitischer Politik in Deutschland zu neuem Leben erweckt. Dies zeigte sich in Versuchen, den wirtschaftlichen Status der Juden und ihre Lebensweise zu beeinträchtigen. Die Beschränkung der Zulassung jüdischer Studenten an den Universitäten, der sogenannte numerus clausus, war z.B. ein altes, bereits im zaristischen Rußland praktiziertes Verfahren ${ }^{38} .1923$ diskutierte der polnische Sejm Anträge zur Beschränkung der Zahl jüdischer Studenten im Hochschulsystem ${ }^{39}$. Da die Verhängung eines numerus clausus gegen Juden im Widerspruch zum Minderheitenvertrag stand, konnte er nicht gesetzlich durchgesetzt werden, praktisch jedoch beschränkten geheime administrative Anweisungen die Zahl jüdischer Hochschulstudenten bereits während der zwanziger Jahre ${ }^{40} .1932$ brachte die Endecja in Polen die Debatte über Zulassungsbeschrän-

33 Akten zur deutschen Auswärtigen Politik (Band III), 9171/E 644 985-91, Der Botschafter in Warschau von Moltke an das Auswärtige Amt, Warschau, 19. 11. 1934, S. 632.

34 Melzer, Relations, S. 208.

35 Korzec, Antisemitism, S. 97.

36 Ebenda, S. 100.

37 Melzer, Relations, S. 213.

38 Die Anfänge des numerus clausus gegen Juden - also die Zulassungsbeschränkung jüdischer Studenten an Hochschulinstitutionen - lagen in dem russischen Gesetz von 1887. Siehe auch: Stillschweig, Juden Osteuropas (Anm. 19), 105-112.

39 Landau, National Minority, S. $163 \mathrm{ff}$.

40 Ebenda, S. 165. - Jüdische Telegraphen Agentur, Nr. 26, 1. 2.1933. 
kungen für Juden an den polnischen Universitäten noch einmal auf die Tagesordnung ${ }^{41}$. Das polnische Recht verhinderte zu jenem Zeitpunkt noch immer eine gesetzlich festgelegte Diskriminierung. In Deutschland hatte sich das "Gesetz zur Wiederherstellung des Berufsbeamtentums" vom 25. April 1933 auch eine Einschränkung von Juden im Bereich der höheren Bildung der Gymnasien und Universitäten zum Ziel gesetzt. Es führte innerhalb kurzer Zeit zu einem drastischen Rückgang der jüdischen Abiturienten und setzte der Möglichkeit der Universitätsbildung für Juden mit deutscher Staatsbürgerschaft ein Ende ${ }^{42}$. Das nationalsozialistische Deutschland führte praktisch einen numerus nullus ein, d.h. jüdischen Studenten wurde der Weg in die Hochschulbildung grundsätzlich versperrt. Angesichts des deutschen Beispiels verstärkte die polnische Rechte ihren Kampf an den polnischen Universitäten. Durch Gewalt und Demütigungen - es wurden separate Sitzbänke für jüdische Studenten in den Hörsälen polnischer Universitäten eingeführt - erreichte die Rechte einen drastischen Rückgang der Zahl jüdischer Studen$\operatorname{ten}^{43}$.

Der Kampf gegen die Juden im Hochschulwesen sollte Karrieren verhindern und den wirtschaftlichen Status von Juden in Polen erschüttern. Die wirtschaftliche Konkurrenz lag überhaupt vielen antisemitischen Maßnahmen in Polen und Deutschland zugrunde. Auch der wesentliche Schritt in diesem Bereich - der antijüdische Wirtschaftsboykott - hatte eine tiefverankerte Tradition in Polen. Der Boykott jüdischer Geschäfte in Deutschland, der am 1. April 1933 begann und sich in verschiedenen Formen und unterschiedlicher Intensität durch die dreißiger Jahre zog, entfachte auch in Polen erneut eine antijüdische Boykottbewegung. In Deutschland verdrängten lokale Polizei und SS bzw. SA jüdische Händler von den Märkten. In Polen verhinderten von der Endecja unterstützte Gruppen den Handel mit Juden, warnten Christen vor dem Einkauf bei jüdischen Unternehmen, kennzeichneten „arische“ Betriebe als solche und veröffentlichten Listen von Polen, die sich nicht an den Boykott hielten ${ }^{44}$. Darüber hinaus unterstützte die polnische Regierung einen Antrag auf Erlaß eines „Arierparagraphen“ in den Satzungen der Berufsverbände und vor allem der Verbände der freien Berufe. Damit trug sie, wie in Deutschland, zur Verdrängung von Juden aus verschiedenen Wirtschaftszweigen bei ${ }^{45}$. Die Auseinandersetzung um das koschere Schlachten mit Argumenten des Tierschutzes aus Motiven der wirtschaftlichen Konkurrenz wurde bereits seit Beginn der zwanziger Jahre geführt. Wie wir bereits zeigen konnten, war zweifellos das Verbot des Schächtens in Deutschland Anfang 1933 jedoch ausreichender Anlaß, um rechte Gruppierungen in Polen zu veranlassen, erneut auf ein Schächtverbot zu drängen.

Andere Maßnahmen griffen den bürgerlichen Status der polnischen Juden an. Die Nürnberger Gesetze fanden in Polen ein positives Echo und wurden zur Nachah-

41 Korzec, Antisemitism, S. $94 \mathrm{f}$.

42 Weiss, Schicksalsgemeinschaft, S. 19-22.

431925 betrug der Anteil jüdischer Studenten an der Gesamtzahl der Studenten an polnischen Universitäten $25 \%$. 1935 war er auf 14,8\% zurückgegangen, 1937-38 erreichte er $10 \%$, 1938-1939 zirka 8,2\% (Angaben nach Enzyklopädie ha-Ivrit und Melzer, No way out, S. 71).

44 Melzer, No way out, S. 45 ff.; Mendelsohn, East Central Europe, S. 73.

45 Melzer, Relations, S. 206; Korzec, Antisemitism, S. 96 f. 
mung empfohlen ${ }^{46}$. In Städten wie Kielce kam es zu Versuchen, über Juden „Rassengesetze" zu verhängen - allerdings ohne Erfolg, da derartige Unterfangen im Widerspruch zur polnischen Verfassung standen ${ }^{47}$. Ende der dreißiger Jahre wurden Initiativen zur Aufhebung der polnischen Staatsbürgerschaft von Juden in Polen ergriffen. Doch trotz des Zusammenhangs zwischen dem Erstarken des Antisemitismus in Polen und den politischen Veränderungen in Deutschland seit 1933 blieben beträchtliche Unterschiede in der Situation von Juden in Deutschland und Polen bestehen. Polen blieb während der dreißiger Jahre bis zum Ausbruch des Zweiten Weltkrieges formal ein demokratischer Staat. Der gesetzliche Status polnischer Juden war in der Verfassung verankert, die eine formale Gleichberechtigung garantierte. Auch wenn das aktive und passive Verhalten der jeweiligen Regierungen, insbesondere das weitgehende Ignorieren der tatsächlichen Verhältnisse, der Verfassung widersprach, konnten Juden in Polen weiterhin einen politischen Kampf führen und sich auf ihre verbürgten Rechte stützen. Außerdem befanden sich während der dreißiger Jahre polnische Juden als politische Vertreter im Sejm und im Senat: In das polnische Parlament wurden im September 1935 vier jüdische Abgeordnete gewählt, Sommerstein, Gottlieb, Rubinstein und Mincberg. Daneben ernannte der Präsident zwei jüdische Senatoren, Moshe Schorr und Jacub Trockenheim. Unter diesen Bedingungen konnten polnische Juden öffentlich um die Bewahrung ihrer Gleichberechtigung kämpfen ${ }^{48}$.

Auf rhetorisch-ideologischer Ebene war das Los der jüdischen Bevölkerung Polens besser als das der deutschen Juden. Die Politik driftete zwar allmählich in den Antisemitismus ab, erhielt jedoch erst Ende der dreißiger Jahre einen ausdrücklich antisemitischen Charakter. In der Regel nahm die Regierung offiziell eine neutrale Position ein. Der polnische Antisemitismus trug - abgesehen von den Standpunkten extremer rechter Kreise - mehrheitlich keine rassistischen Züge. Es war die Kirche, die sich in gewissem Maße vom Rassismus distanzierte, um den Status der zum Christentum Übergetretenen zu schützen ${ }^{49}$. In einem Land wie Polen, in dem die Zahl der zum Christentum übergetretenen Juden äußerst gering war, waren Antisemiten jedoch nicht auf rassistische Argumentationen angewiesen. Anders lagen die Verhältnisse in Deutschland, wo nur schwerlich ein „objektiver“ Maßstab zur Unterscheidung von Juden und Nichtjuden gefunden werden konnte ${ }^{50}$. Darüber hinaus hatte die Rassenlehre in Deutschland eine Rassenhierarchie konstruiert, in der Polen und Slawen in die unterste Kategorie fielen, ein Umstand, der Polen und polnische Rassisten abhielt, von diesem Modell Gebrauch zu machen. Sie sprachen vielmehr von rassischer Andersartigkeit und bauten keine Rassenhierarchie auf ${ }^{51}$. Auch im Hinblick auf die politischen Aktivitäten, die sich aus den verschiedenen Ideologien ergaben, war die Situation der Juden in Polen günstiger als die Lage der

46 Gutman, Polish Antisemitism, S. 106 f.; Melzer, No Way out, S. 72, 92 f.

47 C.V.Z., Nr. 4, 23.1. 1936.

48 Korzec meint, die polnischen Behörden hätten mit Gewalt auf jede Kritik der jüdischen Abgeordneten im Sejm oder im Senat reagiert. Im Vergleich zu Deutschland jedoch, wo Juden in den staatlichen Institutionen politisch nicht repräsentiert waren, war ihre Lage ungleich günstiger; Korzec, Antisemitism, S. $84 \mathrm{f}$.

49 Mendelsohn, East Central Europe, S. 72; Melzcr, Racism, S. 129.

50 Gutman, Polish Antisemitism, S. 106.

51 Melzer, Racism, S. 129. 
deutschen Juden. Polnische Juden besaßen in gewissem Maße die Unterstützung der Sozialisten und zum Teil auch der Intellektuellen und konnten einen offenen Kampf um ihre politischen Rechte führen.

Im Hinblick auf die praktischen Auswirkungen jedoch, die der antisemitischen Politik und Atmosphäre in Form antisemitischer Zwischenfälle im Alltag folgten, war die Situation der polnischen Juden bisweilen wesentlich schlechter als die der deutschen. Entsprechend der traditionellen antisemitischen Praxis in Polen begünstigte die Zentralregierung die Verdrängung polnischer Juden aus verschiedenen Wirtschaftszweigen und förderte den polnischen Sektor durch Benachteiligung des jüdischen. Der Verarmungsprozeß der polnischen Juden, der mit der Weltwirtschaftskrise Ende der zwanziger Jahre eingesetzt hatte, wurde durch diese Politik gefördert. Der neue polnische Regierungschef Slawoj-Skladkowski verkündete bei seinem Amtsantritt, seine Regierung trete dafür ein, daß in Polen niemand in seinen Rechten verletzt werden dürfe. Die Regierung werde sich wie ein guter Hausherr verhalten, der dafür Sorge trage, daß in seinem Hause niemandem Schaden zugefügt werde. Das treffe jedoch nicht auf den wirtschaftlichen Kampf zu. Im Gegenteil! Owszem!

Der Slogan „Owszem!“ verlieh dem Wirtschaftboykott gewissermaßen die offizielle Genehmigung der Regierung52. Es half wenig, wenn die Regierung versuchte, den diskriminierenden Charakter ihrer Wirtschaftspolitik zu vertuschen, weil eine derartige Politik ja im Widerspruch zur polnischen Verfassung stand und dem internationalen Ansehen des Landes schadete. In Deutschland dagegen erlaubte sich das Regime eine offene Verdrängungspolitik. Da jedoch die wirtschaftliche Ausgangssituation der polnischen Juden unvergleichlich schlechter war als die der deutschen Juden, führten die neuen Verhältnisse dazu, daß sie in ihrer Mehrheit einem rasanten Verarmungsprozeß zum Opfer fielen, der sie bis an den Rand ihrer Existenz führte. Dagegen waren die dreißiger Jahre in Deutschland zwar durch eine kontinuierliche, langsame Verschlechterung der wirtschaftlichen Lage der deutschen Juden gekennzeichnet, die jedoch insgesamt immer noch besser blieb als dic Situation der polnischen Juden, die in nicht gekanntem Ausmaße von Hunger und Armut heimgesucht wurden ${ }^{53}$.

Der deutsche Antisemitismus wurde vom Regime gesteuert und instrumentalisiert $^{54}$. Er trat zwar bisweilen „spontan“ auf. Praktisch war er jedoch zur Gänze organisiert und hatte in Zeiten, in denen das Regime kein Interesse an antisemitischen Ausfällen hatte, keinerlei Chancen, sich öffentlich zu äußern ${ }^{55}$. Untersuchungen zur öffentlichen Meinung in Deutschland in den dreißiger Jahren zeigen, daß viele Kreise der deutschen Gesellschaft an der antisemitischen Erosion keinen Anteil hatten und eher Indifferenz, bisweilen sogar Entrüstung angesichts der Phänomene öf-

52 Melzer, No Way out, S. 21; Mendelsohn, East Central Europe, S. 71.

53 Mendelsohn, East Central Europe, S. 74; Bauer, Brother's Keeper, S. 189.

$54 \mathrm{Zu}$ unterschiedlichen Positionen innerhalb der NS-Führung über die Funktion des Terrors in der nationalsozialistischen Politik siehe: Hilberg, Vernichtung, Bd. 1, S. 40-53; zum Zusammenhang von Terror und gezielter Regierungspolitik im Dritten Reich siehe: Adam, Judenpolitik, S. 228.

55 So z. B. in den Jahren 1933-1934, als Deutschland sich um eine Stabilisierung seines internationalen Status bemühte, sowie 1936 vor dem Hintergrund der Olympischen Spiele. 
fentlicher Gewalt zeigten ${ }^{56}$. Tatsächlich ging die Zahl gewalttätiger Zwischenfälle in Deutschland im Laufe der dreißiger Jahre bis zur „Reichskristallnacht“ zurück. Der polnische Antisemitismus dagegen zog seine Kraft aus der Straße. Er war spontaner und gewalttätiger als der deutsche. Er äußerte sich deutlich in körperlichen Übergriffen auf Juden. Polnische Juden waren dieser Gewalt, die deutschen Juden zunächst mehrheitlich erspart blieb, alltäglich ausgesetzt. In den dreißiger Jahren wurden Angriffe gegen Juden eine Routineangelegenheit. Physische Gewalt war weit verbreitet. In den Jahren 1935 und 1936 wurden Hunderte bei gewalttätigen Ausschreitungen in Polen verletzt oder getötet ${ }^{57}$.

\section{Antisemitismus im Spiegel der jüdischen Öffentlichkeit in Polen und Deutschland: Zur Perzeption des Antisemitismus im Nachbarland}

Die gleichzeitige Verschlechterung der Lage von Juden in Deutschland und in Osteuropa war das zentrale Thema der jüdischen Öffentlichkeit schlechthin. Es wurde in der nationalen und internationalen jüdischen Presse ebenso behandelt wie auf zahlreichen Konferenzen. Dabei waren die Hauptbetroffenen - Juden in Polen und Deutschland - die eigentlichen Diskussionsträger, aber auch jüdische Institutionen und Organisationen in aller Welt zeigten besonderes Interesse an diesen Entwicklungen. In vielen Ländern informierte die jüdische Presse ihre Leser über die wirtschaftliche Situation der jüdischen Gemeinden in verschiedenen Staaten. Natürlich war dabei das Interesse an den Verhältnissen im jeweiligen Nachbarland besonders stark. Viele Juden in Polen waren ebenso wie die Zionisten in Deutschland nationaljüdisch orientiert und interessierten sich von daher für die Lage von Juden in anderen Ländern. Auch jene Juden, die eine national-jüdische Existenz oder eine verpflichtende innerjüdische Beziehung ablehnten, hatten bereits vor Beginn der dreiBiger Jahre erkannt, wie sich die Politik gegenüber Juden in verschiedenen Ländern wechselseitig beeinflußte. Die jüdische Gesellschaft des Nachbarlandes diente unter diesen Umständen als Spiegel, durch den Juden ihren Status in der Gesellschaft, in der sie lebten, betrachteten und der es ihnen ermöglichte, einen Blick auf dic - meist bedrohliche - Zukunft zu werfen, die sie und ihre Gemeinden erwartete. Doch mehr noch: Juden in Polen und Deutschland besaßen weitreichende Autonomie in ihren internen Angelegenheiten, insbesondere im Vergleich zu den Einschränkungen, die ihnen in anderen Lebensbereichen auferlegt worden waren. Die jüdische Presse in Polen genoß während der dreißiger Jahre zumeist absolute Pressefreiheit und nutzte diesen Umstand für einen aktiven politischen Kampf um Rechte, Werte und Positionen der jüdischen Bevölkerung. Sie beschäftigte sich intensiv mit den Ereignissen in Deutschland, da sie die von dort ausgehenden Einflüsse auf die Politik der Rechten und der polnischen Regierung fürchtete. Später kam hierzu noch

56 Kulka, Public Opionion; Bankier, German Society; Kershaw, Persecution; ders., Popular Opinion, S. 224-277; Steinert, Hitlers Krieg, S. 236-262. Eine unterschiedliche Einschätzung bei Wildt, Gewalt.

57 Mendelsohn folgt den Angaben Lestschinskys, nach denen in mehr als 150 Ortschaften in Polen insgesamt 1289 Juden bei gewalttätigen Angriffen verletzt wurden; Mendelsohn, East Central Europe, S. 74. 
die Sorge um das Schicksal polnischer Juden im Falle einer Besetzung Polens durch Deutschland.

Die deutsch-jüdische Presse war in ihrer Kritik an der NS-Politik gegenüber Juden völlig eingeschränkt. Die nationalsozialistische Zensur war rückwirkend tätig, was letztlich zu einer Selbstzensur der jüdischen Presse führte ${ }^{58}$. Die Berichterstattung über Antisemitismus in Osteuropa und Polen ermöglichte es der deutsch-jüdischen Presse, diese Einschränkungen zu umgehen und sich trotz aller Zensur mit Antisemitismus zu beschäftigen. Kritik und Befürchtungen, die deutsche Juden um ihre Lage und ihre Zukunft hegten, fanden hier indirekt ihren Ausdruck.

Das Engagement der jüdischen Öffentlichkeit in Polen im Kampf gegen antisemitische Phänomene und die Diskriminierung der Juden in Deutschland war umfassend. In vielen Fällen arbeiteten Parteien und Gruppierungen, die sich ansonsten als politische Konkurrenten verstanden, gemeinsam gegen den Antisemitismus. Dies war ein Ausdruck für eine nationale, alle politischen Unterschiede überwindende Position. In den polnischen und internationalen jüdischen Institutionen herrschte ein allgemeiner Konsens über die Tatsache der wechselseitigen Beeinflussung der antijüdischen Politik in Deutschland und Polen. Die Mobilisierung gegen den deutschen Antisemitismus erfolgte in dem Bemühen, vor ähnlichen Entwicklungen in Polen zu warnen und sie möglichst aufzuhalten. In gewissem Sinne kam hierin eine Umkehr historischer Rollen zum Ausdruck: Traditionellerweise hatte das Judentum im Westen - darunter auch die deutschen Juden - sich für den Schutz und die Garantie der Rechte von Juden in den Ländern Osteuropas eingesetz ${ }^{59}$. In den dreißiger Jahren nun wurde der politische Aktionsrahmen der deutschen Juden eingeschränkt, und sie waren gezwungen - bisweilen mit Genugtuung, manchmal mit Verbitterung - zuzuschauen, wie polnische Juden zu ihren Gunsten eine politische Lobby bildeten.

Erste Anzeichen einer Erschütterung des Status von Juden in Deutschland zeigten sich bereits Anfang der dreißiger Jahre. Die Weltwirtschaftskrise hatte direkt die jüdische Gesellschaft in Deutschland getroffen, während Arbeitslosigkeit und wirtschaftliche Unsicherheit zu einem Erstarken der NSDAP, zu einem Wanken der deutschen Demokratie und zu einem Rückgang politischer Sicherheit und Stabilität in Deutschland geführt hatten. Die polnisch-jüdische Presse hatte nach dem Wahlerfolg der NSDAP im September 1930 begonnen, den Weg dieser Partei zu verfolgen 60 . Sie berichtete über die Aktivität der NSDAP, ihre Absichten und die Gründe ihres Erfolges sowie über die zu erwartenden Auswirkungen für das Schicksal der polnischen Juden. Trotz eines gewissen Pessimismus glaubten viele Zeitungen, der extreme Antisemitismus der Nationalsozialisten würde sich zügeln, wenn Hitler Reichskanzler werden würde, da er dann doch wohl notwendigerweise andere Parteien an der Regierung beteiligen oder sich anderen Regierungszwängen beugen müßte. Parallel dazu berichtete die polnisch-jüdische Presse ausführlich und systematisch über antisemitische Aktivitäten in Polen selbst bzw. über die entsprechenden Verbindungen zwischen Polen und dem nationalsozialistischen Deutschland ${ }^{61}$.

58 Freeden, Jüdische Presse, S. $20 \mathrm{f}$.

59 Gutwein, Jewish Diplomacy.

60 Sagi/Lowe, Rescarch Report, S. 400 ff.

61 Ebenda, S. 401. 
Der Vergleich zwischen den Verhältnissen in Polen und Deutschland um 1933 paßte nicht zu dem Selbstverständnis, das die meisten deutschen Juden zu jener Zeit hatten. Gefangen in den Vorstellungen vergangener Zeiten, wiesen viele deutsche Juden die Möglichkeit strikt zurück, zwischen beiden Gemeinschaften könnten irgendwelche Entsprechungen bestehen. Das überparteiliche Israelitische Familienblatt protestierte lautstark gegen die Einmischung polnischer Juden in Angelegenheiten der deutschen Juden:

„Solange die Not der Juden in Polen so außergewöhnlich ist wie jetzt, sollten die Körperschaften in Warschau sich zunächst mit dieser Not beschäftigen und davon absehen, eine sicherlich ungewollte Entlastungsoffensive für die Regierung des Herrn Pilsudski vorzunehmen. Zur Lage der deutschen Juden Stellung zu nehmen und die hierfür geeignet erscheinenden Hilfsmaßnahmen zu treffen, ist Sache der deutschen Juden selbst."62

Dies war eine besonders eindeutige Stellungnahme, die jedoch das Selbstverständnis der deutschen Juden zu jener Zeit treffend ausdrückte. Ein weiteres Beispiel für diese Haltung findet sich in der Zeitung der jüdischen Gemeinde zu Breslau. Dort wurde Mitte 1932 ein Vorschlag eines Lemberger Juden, für die Zeitung Artikel über die Situation der Juden in Polen zu übersetzen, mit dem Argument zurückgewiesen, für Berichte über die Lage von Juden in Polen und ähnliche Themen gebe es augenblicklich keinen Platz in der Zeitung ${ }^{63}$.

Die Zunahme des Antisemitismus in Deutschland setzte derartigen Äußerungen ein Ende. Gezwungenermaßen mußte die jüdische Presse in Deutschland anerkennen, daß zwischen den politischen Ereignissen in Deutschland und Polen doch eine Verbindung bestand. Die Zeitung des Central Vereins veröffentlichte schon 1932 einen Beitrag, der die Verkettung antisemitischer Ausfälle in Polen beschrieb, die an den Universitäten einsetzten und sich über viele Städte ausbreiteten ${ }^{64}$. Die Zeitung warnte ihre deutschen Leser zum Abschluß des Artikels, sich nicht damit zu begnügen, ihrer Abscheu vor ähnlichen Vorkommnissen an deutschen Universitäten Ausdruck zu verleihen, sondern vielmehr entschieden gegen derartige Vorfälle vorzugehen, um zu verhindern, daß Universitäten zu einer Quelle der Gewalt in ganz Deutschland würden. Die zionistische Jüdische Rundschau veröffentlichte Ende 1932 - neben einem visionären Leitartikel über Hitlers bevorstehende Regierungsübernahme und deren Auswirkungen auf die Juden - einen detaillierten Beitrag über aktuelle Gewalttaten gegen Juden in polnischen Städten ${ }^{65}$. Es war ja ohnehin die klassische zionistische Auffassung, daß das Leben in der Diaspora Juden fortwährend einem potentiellen Antisemitismus aussetzte. In diesem Sinne war es selbstverständlich, die Vorfälle in Deutschland und Polen in Zusammenhang zu bringen.

Hitlers Machtübernahme erschütterte weltweit die jüdische Öffentlichkeit, auch wenn sie nicht gänzlich unerwartet eingetreten war. Zahlenmäßig war die Bedeutung des deutschen Judentums im Vergleich zur Größe der jüdischen Bevölkerung

62 Israelitisches Familienblatt, Unerwünschte Einmischung, 14. 7. 1932, bei: Margaliot, Political Reaction, S. 120.

63 ZIH, Synagogengemeinde zu Breslau, Akt. Nr. 88, Die Schriftleitung des Gemeindeblattes an Herrn O. Preminger am 1. 4. 1932.

64 C.V.Z., 9. 12. 1932.

65 JR, 6. 12. 1932, bei: Margaliot, Political Reaction, S. 108. 
in Polen zweitrangig. In politischer Hinsicht jedoch kam den Ereignissen in Deutschland eine entscheidende Bedeutung für das Schicksal der Juden in Osteuropa zu. In den ersten Wochen nach dem Sieg Hitlers hielt die polnisch-jüdische Presse weiterhin an der Auffassung fest, Hitler könne seine Drohungen nicht in die Tat umsetzen, ja es sei überhaupt zweifelhaft, ob er lange als Reichskanzler amtieren werde. Ähnliche Stimmen wurden in anderen Ländern laut ${ }^{66}$. Als Deutschland nach einigen Monaten begann, Juden aus öffentlichen Ämtern zu entlassen und aus den freien Berufen zu verdrängen, als es zum Boykott jüdischer Geschäfte und Unternehmen kam, als man hörte, daß Intellektuelle ins Exil gingen oder vertrieben wurden, als sich Informationen über Gewalttätigkeiten in Deutschland verbreiteten, da begann die polnisch-jüdische Presse Besorgnis und Entsetzen zu zeigen ${ }^{67}$. Polnische Juden, so hieß es in der Presse, dürften die Größe der ihnen drohenden Gefahr nicht unterschätzen. Hitlers Wahlsieg am 5. März möge ihnen als ernsthafte Warnung gelten. Auch mögen sie wissen: Die „polnischen“ Hitleristen seien nicht sanfter in ihrem Krieg und in ihrem Sieg als Hitlers Anhänger in Deutschland ${ }^{68}$. Ein Mitglied des Hechalutz (zionistischer Dachverband zu Zwecken der Emigration) ergänzte, jener deutsche Jude, der in dem polnischen Juden stets nur einen Sündenbock für seine Probleme gesehen habe und dem er für alles, was ihm widerfahren sei, die Schuld hatte zuweisen können, säße nun in seinem Zimmer und warte auf eine Möglichkeit, auszuwandern. Über Nacht sei er zum wandernden Juden geworden. Groß sei die Katastrophe, die über die deutschen Juden gekommen sei. Doch eigentlich könne keiner der Zeitgenossen den Umfang der Katastrophe wirklich abschätzen. Die Lage der deutschen Juden entspreche in allem der Situation der Juden in Osteuropa, ja sei vielleicht furchtbarer als die Not aller anderen ${ }^{69}$.

Nach Hitlers Machtübernahme scheute die polnisch-jüdische Presse keine Anstrengung, Zeugnisse aus erster Hand über die Ereignisse in Deutschland zu bringen $^{70}$. Dennoch bewahrte sie eine gewisse Kühle und Distanz: Die Zeitung Haynt rief ihre Leser auf, sich nicht auf Provokationen der polnischen Rechten einzulassen, die von den Nationalsozialisten beeinflußt seien ${ }^{71}$. Die Politik der Nationalsozialisten wurde von der polnisch-jüdischen Presse im zionistischen Lager noch nicht als die Verwirklichung des nationalsozialistischen Programms zur totalen Verdrängung der Juden aus allen Lebensbereichen interpretiert. Die Zeitung des Bundes, die in jiddischer Sprache erscheinende Neue Volkszeitung, verstand die Ereig-

66 Die britische Presse verfolgte die Entwicklung der NSDAP seit 1930, glaubte jedoch, es handele sich um eine politische Partei wie jede andere, die sich in Zukunft ciner der Koalitionen anschließen und im Rahmen des parlamentarischen Systems aufgehen werde. Diese Einschätzung änderte sich auch unmittelbar nach Hitlers Ernennung zum Reichskanzler nicht. Die Presse erwartete einen raschen Untergang der Hitler-Regierung, obwohl es dafür keine offensichtlichen Anzeichen gab. - Shamir, Before the Holocaust, S. $12 \mathrm{f} ., 17 \mathrm{ff}$., 26.

67 Sagi/Lowe, Research Report, S. $400 \mathrm{ff}$.

68 Die Zukunft (Zeitung der Hechalutz-Weltorganisation), Z. Rosenstein, Vor dem 18. Kongreß, 5. 5. 1933.

69 Die Zukunft, Das Judentum im neuen Deutschland, 5. 5. 1933, S. 10.

70 Der neue Morgen, In den blutigen Kellern der Hitler-Inquisition. Schauderliche Tatsachen und Bilder aus der deutschen Hölle (jiddisch), 8. 5. 1933. Die Zeitung schreibt über die große Schwierigkeit, Informationen zu erhalten, da Juden sich fürchteten, über ihre Lage zu berichten.

71 Hierzu im Bericht bei: Sagi/Lowe, Research Report, S. 401. 
nisse in Deutschland als Teil des Klassenkampfes. Sie glaubte bei wohlhabenden Juden eine gewisse Genugtuung über Hitlers Regierungsübernahme bemerken zu können und interpretierte die Verfolgung von Juden als Teil der allgemeinen Verfolgung der Arbeiterklasse.

Neben den kontinuierlichen Zeitungsberichten organisierten sich weite Teile der jüdischen Öffentlichkeit in Polen zugunsten der deutschen Juden. Der Umfang des jüdischen Protestes in Polen, im Vergleich zu anderen jüdischen Gemeinden, war außerordentlich groß, insbesondere, wenn man die wirtschaftliche und politische Not der polnischen Juden zu jener Zeit in Erwägung zieht. Der Präzedenzcharakter des deutschen Antisemitismus und seine direkte Relevanz für die Lage der polnischen Juden waren sicherlich ein Grund dafür. Im April 1933 trat der „Kongreß der jüdischen Gemeinden und Organisationen Polens“ in Warschau zusammen, um die Lage der deutschen Juden zu erörtern ${ }^{72}$. An dem Kongreß nahmen Vertreter von 364 jüdischen Gemeinden und 128 Organisationen teil. Yehoshua Gottlieb, der den Kongreß im Namen des „Komitees der jüdischen Gemeinden und Organisationen Polens" eröffnete, betonte das große Entsetzen, das die politischen Entwicklungen in Deutschland hervorgerufen hätten, gerade weil sie sich gegen deutsche Juden richteten, die sich doch immer der deutschen Kultur zugehörig gefühlt hatten. Gottlieb betonte freilich, die Proteste polnischer Juden gegen die Ereignisse in Deutschland seien nicht vom $\mathrm{Haß}$ gegen das deutsche Volk getragen. Er wies außerdem darauf hin, daß man unbedingt zwischen den Ereignissen in Deutschland einerseits und den Beziehungen zwischen deutschen und jüdischen Minderheiten in Polen unterscheiden müsse ${ }^{73}$. Zum Abschluß gab der Kongreß vier Erklärungen heraus: Er protestierte gegen die Verdrängung von Juden aus der deutschen Wirtschaft; er setzte den Akzent auf die Auswanderung, insbesondere nach Palästina, als grundlegende Lösung der "Judenfrage" in Deutschland, wobei aber auch andere Länder aufgerufen wurden, ihre Tore für die Flüchtlinge zu öffnen; er wandte sich an die jüdischen Gemeinden in verschiedenen Ländern mit der Aufforderung, die jeweiligen Regierungen unter Druck zu setzen, damit sie die Einwanderung deutscher Juden in ihre Länder gestatteten; und schließlich forderte der Kongreß Deutschland auf, Religions- und Glaubensfreiheit zu gewähren, was sich insbesondere auf das Schächtverbot bezog. Gottlieb zeigte sich zufrieden, daß der Kongreß erfolgreich verschiedene Strömungen des polnischen Judentums in seinen Reihen hatte vereinigen können. Die Londoner Times schrieb sogar, es habe sich bei der Tagung um die größte jüdische Versammlung gehandelt, die jemals in Polen stattgefunden habe ${ }^{74}$.

Ebenfalls im April 1933 weigerte sich die Delegation des Verbandes jüdischer Studenten in Polen, an dem internationalen Studentenkongreß teilzunehmen, der 1933 in Ettal bei München stattfinden sollte. Die polnisch-jüdischen Studenten hielten

72 Jüdische Zeitung, Kongreß der jüdischen Gemeinden und Organisationen Polens in Warschau, Nr. 17, 28. 4. 1933.

73 Polnische Juden scheuten keine Anstrengung, um weiterhin gute Beziehungen zu der deutschen Minderheit in Polen zu unterhalten; siehe z.B. für Lodz: $J R$, Deutsche und Juden in Polen, Nr. 34, 28. 4. 1933. Gleichzeitig schränkten sie infolge der Ereignisse in Deutschland die Beziehungen zu anderen Minderheiten sowie ihre Bereitschaft, die polnische Regierung zu unterstützen, ein. - Korzec, Antiscmitism, S. 80.

$74 \mathrm{JR}$, Jüdischer Kongreß in Polen, Nr. 34, 28. 4. 1933. 
diesen Ort für ungeeignet, um demokratische Auffassungen zum Ausdruck zu bringen. Außerdem wollten sie sich mit der Delegation des deutsch-jüdischen Studentenverbandes solidarisch erklären, dem die Teilnahme an dem Kongreß versagt war ${ }^{75}$. Die Geschäftsführung des polnischen Rabbinerverbandes rief Ende Mai 1933 alle Rabbiner auf, in ihren Predigten am Schabbat die Lage der Juden in Deutschland zu erwähnen und die Gläubigen aufzufordern, bei den allgemeinen Sammelaktionen für deutsche Juden erhöhte Opferbereitschaft zu zeigen ${ }^{76}$. So ging der Protest gegen die Vorkommnisse in Deutschland durch alle Teile der jüdischen Öffentlichkeit in Polen.

Der Umfang der gegen die Nationalsozialisten gerichteten Aktionen von jüdischer Seite in Polen führte dazu, daß polnische Juden ein Selbstverständnis entwikkelten, demzufolge sie besonders hartnäckig gegen den Nationalsozialismus kämpften. Moshe Kleinbaum (Sneh) versuchte, diesen Eindruck abzuschwächen. Als Reaktion auf den Kongreß der jüdischen Gemeinden in Polen Anfang 1933 schrieb Sneh, der Kongreß habe nichts anderes als ohnehin selbstverständlichen, unverbindlichen Protest hervorgebracht ${ }^{77}$. Sneh meinte, wenn die jüdische Öffentlichkeit wirklich etwas unternehmen wolle, müsse sie intensiv globalen Druck auf alle Staaten ausüben, damit dem Nationalsozialismus der Krieg erklärt werde. Die Wurzel des Problems sah Sneh in der inneren Aufsplitterung polnischer Juden in Zionisten, Orthodoxe und Assimilierte, wodurch ein gemeinsames Vorgehen zugunsten eines positiven Zieles verhindert und das Handeln polnischer Juden auf „antihitleristische Demonstrationen, auf negative Momente" beschränkt werde.

Interessanterweise sorgten sich auch in anderen Ländern gerade polnische Juden um die Entwicklungen in Deutschland. 1933 wurde in Paris das Komitee zum Schutze der Juden in Mittel- und Osteuropa gegründet, dem französische und osteuropäische Juden, aber auch nichtjüdische Franzosen angehörten, die sich politisch für Juden in Deutschland, Polen, Rumänien und anderen Ländern einsetzen woll$\operatorname{ten}^{78}$. Zu diesem Zwecke wurden Broschüren über die Situation von Juden in diesen Ländern gedruckt und in diplomatischen Kreisen verteilt. Darüber hinaus setzte sich das Komitee bei den französischen Einwanderungsbehörden für jüdische Flüchtlinge ein, die durch eine Ausweisung aus Frankreich gefährdet waren. Auch der Verband der osteuropäischen Gemeinden in Frankreich beteiligte sich an dem Engagement für deutsche Juden. Die Vertreter der Organisation kamen Anfang 1934 in Paris zusammen und riefen die osteuropäischen Juden in Frankreich auf, mindestens eine Million Franc für deutsche Juden aufzubringen ${ }^{79}$. Ehrenredner der Versammlung war Baron Robert de Rothschild, der diese Gelegenheit nutzte, um den reichen Emigranten ins Gewissen zu reden, die sich gegenüber ihren Brüdern in Not gleichgültig verhielten und abweisend zeigten.

75 SoA, 1230/1/21, Alexander Teich (Jüdischer Hochschulausschuß Wien) an Dr. Walter Kotsching (Internationaler Studenten Service, Genf) am 25. 4. 1933.

76 Jüdische Zeitung, Nr. 21, 2. 6. 1933.

77 „Odwrotna strona medalu ... Rozwazania na temat jednos'ci zydowskiej“, Opinja, in: Sneh, Writings, S. 212-215.

78 Jiddische Organisationen und Institutionen in Paris 1939 [...] bearbeitet von A. A., in: A. Tscherikover, Juden in Frankreich. Studien und Materialien (jiddisch), S. 263-248, hier: S. 261.

79 Jüdische Zeitung, Nr. 4, 28. 1. 1934. 
$\mathrm{Zu}$ ähnlichen Aktionen kam es auch in den Vereinigten Staaten. Die Federation of Polish Jews in America trat 1933 mit einer Erklärung hervor, in der sie sich mit den führenden jüdischen Organisationen zum Schutze der Rechte deutscher Juden einig erklärte ${ }^{80}$. In einem Bericht der New York Times hieß es, in gleichem Zusammenhang hätten die Vertreter der Federation auch auf Ereignisse in Polen Bezug genommen und erklärt, "die Diskriminierung der Juden in Polen repräsentiert nicht den Willen des polnischen Volkes oder der polnischen Behörden“. Die Zeitung berichtete, die Vertreter hätten der polnischen Regierung für ihre „hervorragenden Bemühungen zugunsten jüdischer Flüchtlinge aus Deutschland“" gedankt. Die Federation of Polish Jerws begnügte sich jedoch nicht allein mit Erklärungen. Sie knüpfte Verbindungen mit dem polnischen Konsulat in New York und versuchte, die polnische Diplomatie zum Schutze der Rechte von polnischen Juden in Deutschland einzusetzen ${ }^{81}$.

Ze'ev Jabotinsky, der Anführer der zionistischen Revisionisten, behauptete 1933, polnische Juden protestierten gegen den Hitlerismus, weil sie Gefallen in den $\mathrm{Au}-$ gen der polnischen Obrigkeit finden wollten ${ }^{82}$. Bis zur Unterzeichnung des Nichtangriffspaktes zwischen Polen und Deutschland von 1934 konnte wohl tatsächlich davon ausgegangen werden, daß eine Kritik an der Lage der Juden in Deutschland von den polnischen Regierungsbehörden positiv beurteilt wurde, ein Umstand, der polnisch-jüdische Organisationen durchaus zu entsprechenden Äußerungen hätte motivieren können. Polnisch-jüdische Politiker erklärten ausdrücklich, angesichts der Spannungen zwischen Deutschland und Polen müsse man die polnische Seite im Kampf gegen Deutschland unterstützen und die Kritik an der polnischen Regierungspolitik entsprechend einschränken ${ }^{83}$. Der Nichtangriffspakt zwischen Deutschland und Polen verschob die Konfrontationslinien und stellte die weitere Zusammenarbeit polnischer Juden mit der polnischen Regicrung gegen das nationalsozialistische Deutschland in Frage ${ }^{84}$.

Die deutsch-jüdische Öffentlichkeit bewertete die polnisch-jüdischen Bemühungen und Initiativen keineswegs positiv. Der Haynt berichtete, deutsche Juden hätten sich den antihitleristischen Aktivitäten der polnischen Seite gegenüber ablehnend gezeigt ${ }^{85}$. Die Zeitung des Central Vereins berichtete in skeptischem Ton über das große Interesse, das polnische Juden „drüben“ für die Lage deutscher Juden zeigten $^{86}$. Wir dürfen nicht vergessen, daß parallel zur antisemitischen Politik in

80 New York Times, Hail Senators' stand against Nazis' bias, 12. 6. 1933.

81 AAN, Amb. Rp. w Berlinie, Akt. Nr. 895, Federation of Polish Jews in America on the Consulate of the Republic of Poland, New York on 18.4.1934.

82 He-Atid, Nr. 144, 30. 5. 1933.

83 Korzec, Antisemitism, S. 79 f.

84 Sneh meinte, Juden müßten sich der deutsch-polnischen Annäherung gerade aufgrund polnisch patriotischer Erwägungen widersetzen. Sneh sah durch die Annäherung an Deutschland die polnische Unabhängigkeit und Zukunft bedroht. Außerdem glaubte er, daß infolgcdessen das Bild Polens in der Weltöffentlichlkcit negativ beeinflußt werde. Haynt, Wohin gehen wir? (jidd.), 18. 6. 1934, in: Sneh, Writings, S. $293 \mathrm{ff}$.

85 Haynt, Erstes jüdisches, antihitleristisches Treffen in Posen, 19. 1. 1934.

86 Nach der Meldung der C.V.Z. umfaßte die aktuelle Berichterstattung über die Entwicklungen in Deutschland in den jüdischen Zeitungen in Polen eine ganze Seite. Daneben hätten die Zeitungen noch weitere allgemeine Stellungnahmen abgedruckt; C.V.Z., Ein Streifzug durch die Nachbarschaft, Nr. 26, 28. 6. 1934. 
Deutschland nach Hitlers Machtübernahme auch der Antisemitismus in Polen kontinuierlich dramatisch zunahm. Die C.V.-Zeitung berichtete, wie polnische Juden tendenziell im Aufklärungskampf gegen den Antisemitismus resigniert hätten. Sie versuchte daher, ihnen Ratschläge zu erteilen und zu vermitteln, wie wichtig es sei, sich grundloser antisemitischer Beschuldigungen zu erwehren, wenn sie schrieb:

„Aber muß nicht ein Angeklagter, der unschuldig ist, seine Unschuld noch beteuern, wenn er zu Tode verurteilt wird? Auch wenn es ihm nicht das Leben rettet! Um der Wahrheit willen, nicht um des Lebens willen." 87

Auch die Jüdische Rundschau war sich der wechselseitigen Beeinflussung antisemitischer Strömungen in Europa bewußt. Anders jedoch als die C.V.-Zeitung erteilte sie polnischen Juden keine Ratschläge. Die Rundschau zitierte vielmehr den polnischen Regierungssprecher, daß ein Übergreifen der antisemitischen Agitation nach Polen von der Regierung auf jeden Fall verhindert werden würde. Die Vorstellung, daß die nationale Größe durch das Zerstören jüdischer Läden begründet werden könnte, hätte in der freien polnischen Republik keinen Platz ${ }^{88}$. Dieses Aufgreifen eines offiziellen Statements ermöglichte es der zionistischen Zeitung, den deutschen Antisemitismus anzugreifen und vor seinen Einflüssen zu warnen.

Alle jüdischen Zeitungen in Deutschland unterschieden deutlich zwischen dem Eindringen antisemitischer Propaganda in die polnische Gesellschaft und den Positionen der polnischen Regierung, die diese Phänomene offiziell ablehnte. Der Israelit zitierte Aron Levin, Präsident des Landesverbandes der Agudat Israel in Polen:

„Wenn man die geographische Lage Polens betrachtete, wo im benachbarten Sowjetrußland einerseits eine allgemeine jüdisch-religiöse Verfolgung herrscht, und in Deutschland andererseits die Juden ihrer bürgerlichen Gleichberechtigung beraubt werden, so sind die Juden in Polen, dank der Regierung des Marschalls Pilsudski wie auf einer Insel gegen die Einflüsse der östlichrussischen Religionsverfolgung und des westlichen Antisemitismus beschützt." 89

Demnach hatte Der Israelit wie alle jüdischen Zeitungen in Deutschland erkannt, $\mathrm{da} ß$ der staatsbürgerliche Status der Juden in Polen günstiger und geschützter war als der der deutschen Juden. In der deutsch-jüdischen Geschichte hatten Juden ihrem staatsbürgerlichen Status stets große Bedeutung beigemessen, so daß diese Erkenntnis der Zeitung einem Bewußtseinswandel gleichkam.

Einen Monat nach der Ernennung Hitlers zum Reichskanzler verglich der britische Zionist Lord Alfred Monde Melchett den deutschen Antisemitismus, den er als einen "kulturellen Antisemitismus“ bezeichnete, mit dem polnischen „wirtschaftlichen Antisemitismus"90. Melchett sah auch den Antisemitismus in Deutschland als ein „künstliches Produkt“, da der Anteil der Juden an der Gesamtbevölkerung kaum ein Prozent betrug. Der polnische Antisemitismus dagegen sei ein „Staatsproblem", da der Anteil der Juden in diesem Land 10\% der Gesamtbevölkerung erreichte. Dieses Problem müsse die polnische Regierung in Zusammenarbeit mit den Juden im staatlichen Interesse lösen. In den ersten Jahren des NS-Regimes vertraten viele Juden eine ähnliche Position wie Lord Melchett. Nach dieser Unterscheidung

87 C.V.Z., Ein Blick nach draußen, Nr. 25, 1. 6. 1934.

$88 \mathrm{JR}$, Abgewehrte jüdische Ausschreitungen, Nr. 23, 21. 3. 1933.

89 Der Israelit, Zur Lage der Juden in Polen, Nr. 33, 17. 8. 1933.

90 Jüdische Telegraphen Agentur, Jg. XII, Nr. 42, 20. 2. 1933. 
hatte die „Judenfrage" in Deutschland politisch-kulturelle Ursachen, während sie in Polen im wesentlichen wirtschaftlicher Natur war, eine Diagnose, die im Laufe der Jahre an Gültigkeit verlor: Die NS-Wirtschaftspolitik führte zur allmählichen Verarmung der jüdischen Bevölkerung in Deutschland, während die Entwicklungen in Polen über die bekannte wirtschaftliche Not hinaus eindeutig Züge eines ideologisch-politischen Antisemitismus zeigten.

Im Herbst 1935 kam der Jüdische Kongreß in Warschau zusammen, um nach dem Erlaß der Nürnberger Gesetze die Verfolgung von Juden in Deutschland zu erörtern $^{91}$. Der Kongreß - an dem mehrere hundert Juden teilnahmen - erkannte, daß sich die Lage der Juden in Deutschland keineswegs verbessert hatte. Die Nürnberger Gesetze wurden als der gesetzliche Ausdruck für eine praktisch bereits seit langem herrschende Diskriminierung begriffen. Der Kongreß rief zur jüdischen Solidarität auf, um den deutschen Juden ihre Menschenrechte und Menschenwürde zurückzugeben. Er forderte die polnischen Juden auf, den Rassismus so lange zu bekämpfen, bis deutsche Juden wieder in ihre alten Rechte eingesetzt seien. Gleichzeitig wies der Kongreß auf die erhebliche Verschlechterung der wirtschaftlichen Lage polnischer Juden in Deutschland hin. Zum Abschluß des Kongresses wurde das Vereinigte Komitee zum Kampf gegen die Verfolgung der Juden in Deutschland ins Leben gerufen. Die Erklärungen des Kongresses weisen auf die grundsätzliche Bedeutung hin, die das polnische Judentum dem Kampf für die bürgerliche Gleichberechtigung der deutschen Juden beimaß, aber auch auf das Ende der Epoche, in der die Kritik an den Ereignissen in Deutschland der polnischen Regierung hätte schmeicheln können. 1935 war, wie erwähnt, das Jahr, in dem sich die Situation der polnischen Juden zu verschlechtern begann. Ausbrüche eines aggressiven, gewaltsamen Antisemitismus folgten einander in regelmäßigen Abständen in Polen. Jakob Lestschinsky verglich zu jener Zeit den Antisemitismus in Polen und Deutschland:

„In Hitlers Deutschland unserer Tage [hilft auch] die wildeste Propaganda der Minister und alle offenen Aufrufe zu Pogromen der Regierungsvertreter [nichts]. Die Öffentlichkeit, im weitesten Sinne des Wortes, bleibt Aufrufen zum Pogrom gegenüber gleichgültig. Wenn die Regierung also an Pogromen interessiert ist, dann ist sie gezwungen, ihre treuen Knechte aus der Hitler-Partei auszuschicken ... Völlig anders ist die Situation jetzt in Polen. Die Regierung kämpft gegen Pogrome, schwach, ohne Entscheidungsfreude, ohne Eifer, in nicht ausreichend effektiver Weise und nicht entschieden genug ... Aber die Pogrome werden nicht, von oben" angeordnet und ausgeführt, sondern wachsen von unten, aus der breiten Masse der Intelligenz, der kleinen Eigentümer, aus der Arbeiterschaft und dem Händlerstand, aus den Verarmten, die aus ihrem Stand verdrängt wurden." 92

Tätliche Angriffe und Verletzungen an Leib und Seele waren, wie erwähnt, in Polen wesentlich häufiger als in Deutschland. Die relativ wenigen Vorfälle physischer Gewalt im NS-Deutschland erschwerten es bisweilen, die politische Situation richtig einzuschätzen. Die Jüdische Rundschau nahm bereits im Februar 1933 zur Frage des physischen Terrors und der antisemitischen Gewalt in Deutschland Stellung und schrieb, die hohe kulturelle Tradition Deutschlands verlange eine gemäßigtere Form antisemitischer Ausfälle als im zaristischen Rußland ${ }^{93}$. Die historische Forschung blickt auf die Rolle von Gewalt und Terror des NS-Regimes aus einer späten Per-

91 PAAA, R 99458, Deutsche Botschaft in Warschau an das Auswärtige Amt, 21. 1. 1936.

92 Lestschinsky, Erev Churban, S. 134.

93 Fraenkel, Zionist Policy, S. 42. 
spektive. Für Pogrome, wie sie in Osteuropa üblich waren, gab es im nationalsozialistischen System zunächst keinen Raum. Sie hätten auch wohl kaum die Unterstützung der breiten Öffentlichkeit gefunden. Für die Zeitgenossen war es bisweilen schwierig, mit den Unterschieden zwischen den antisemitischen Phänomenen in Deutschland und Polen umzugehen. David Ben-Gurion war infolge seines Besuches in Polen im Sommer 1936 davon überzeugt, die Situation des polnischen Judentums, in einem Alptraum leben zu müssen, die permanenten Pogrome, die physische, wirtschaftliche und ethische Situation, sei vielleicht viel schrecklicher als in Deutschland - sie stumpfe die Wahrnehmung der Außenstehenden $a b^{94}$. Auch Bernard Kahn, der Repräsentant des Joint in Europa, meinte, den deutschen Antisemitismus dem polnischen „vorziehen“ zu können; der deutsche Antisemitismus sei unverhüllt und daher ehrlicher als der polnische ${ }^{95}$.

Die jüdische Öffentlichkeit in Deutschland verfolgte die neuen antisemitischen Tendenzen in Polen seit 1935 sehr genau. Die C.V.-Zeitung nahm eine regelmäßige Kolumne über die Situation der Juden in den benachbarten Ländern auf ${ }^{96}$. Im Rahmen dieser Kolumne erfolgte eine umfangreiche Berichterstattung über Osteuropa. Angesichts der dort herrschenden schwierigen Verhältnisse konnte man die für vorangehende Jahre adäquate Differenzierung eines Antagonismus zwischen Oppositionskreisen und Regierungspositionen nicht länger aufrechterhalten. Die C. V.-Zeitung berichtete zwar über einen „Landeskongreß der jüdischen Kämpfer des polnischen Befreiungskrieges", der feierlich im Warschauer Rathaus in Anwesenheit des stellvertretenden polnischen Außenministers eröffnet und auf dem die Rolle und Bedeutung der Juden für die Befreiung Polens hervorgehoben worden war ${ }^{97}$. In diesem Bericht klang ein längst vergangener Diskurs an, an dem sich deutsche Juden in der Weimarer Zeit beteiligt hatten. Doch die Mehrheit der Zeitungsberichte aus Polen in jener Zeit konnte den Verfall des Status von Juden in Polen nicht ignorieren. Die Jüdische Zeitung berichtete über den Suizid des Gemeindevorsitzenden im polnischen Lomza nach einer Protestdemonstration gegen die Lage der polnischen Juden. Als Grund für den Selbstmord hatte der Gemeindevorsitzende in einem Abschiedsbrief den Schmerz über das Schicksal der Juden in Polen angegeben. Die Zeitung wußte weiterhin zu berichten, daß der einzige Sohn des Gemeindevorsitzenden im Jahre 1920 in den russisch-polnischen Kämpfen auf polnischer Seite gefallen war ${ }^{98}$. Die Auswahl derartiger Nachrichten war keineswegs zufällig, sondern zielte direkt auf deutsche Juden, die infolge des scharfen Gegensatzes zwischen ihrem nationalen Beitrag in der Vergangenheit und dem Verlust ihres staatbürgerlichen Status in der Gegenwart ihre Selbstsicherheit verloren hatten und in tiefe Frustration geraten waren.

In der Vergangenheit hatte die deutsch-jüdische Presse dazu geneigt, die entschiedene Position der polnischen Regierung gegen den Antisemitismus zu betonen. Noch Anfang 1936 hielt sie an dieser Auffassung fest. Die Jüdische Rundschau berief sich wie früher auf offizielle polnische Stellen: Man zitierte Innenminister

94 Zitiert bei: ebenda, S. 240.

95 Bauer, Brother's Keeper, S. 188.

96 Der Titel der Kolumne hieß: „Die Zerstreuung der Juden über die Erde.“

97 C.V.Z., Nr. 2, 9. 1.1936.

98 Jüdische Zeitung, Zur Lage der Juden in Polen, Nr. 5, 21. 2. 1936. Über eine Selbstmordwelle berichet auch Lestschinsky, Erev Churban, S. 142-149. 
Raczkiewich: „Ein gesunder Nationalismus, aufgebaut auf stolzem Volksbewußtsein und ehrlicher Gemeinschaftsarbeit, sei ein schöpferischer Quell. Der Nationalismus der Nationaldemokraten sei aber ein krankhafter." "99 Auch hier hatte die Zeitung wieder den indirekten Weg gewählt, um ihre eigene Meinung über den Charakter des Nationalsozialismus und den Unterschied zwischen national und nationalistisch zum Ausdruck zu bringen. Doch von Monat zu Monat wurde es schwieriger, zwischen der Position der gewalttätigen Rechten und der Haltung der Regierung zu unterscheiden. Heftige antisemitische Ausfälle und Übergriffe brachen in Polen auf Initiative der Anhänger des rechten Lagers aus und erreichten ihren Höhepunkt in dem Pogrom rechter Kräfte gegen Juden in der Stadt Przytyk bei Radom am 10. März 1936. Bei diesem Pogrom wurden drei Juden ermordet und sechs verletzt. Das Ausmaß an Gewalt, der Verlauf der Ereignisse und die Erkenntnis, daß dies alles hätte vermieden werden können, wiesen eindeutig auf Versäumnisse der polnischen Regierung hin. Viele polnische Juden fühlten sich an die Pogrome der Jahre 1918-1920 erinnert und begannen, Zweifel an der Unterscheidung zwischen Massen und Regierung in Polen und Deutschland zu hegen. Die jüdische Presse in Deutschland mußte einsehen, daß die polnische Regierung im Kampf gegen den Antisemitismus letztlich unzuverlässig war. Die lokale jüdische Zeitung in Danzig berichtete über Beschwerden des Sejm-Abgeordneten der Agudat Israel, Mincberg, der den Mangel an Bereitschaft der Staatsorgane - sprich: der Polizei - beklagte, die Regierungspolitik im Kampf gegen den Antisemitismus durchzusetzen ${ }^{100}$. Die Jüdische Rundschau warnte, „die Zentralregierung verurteilt die antijüdische Bewegung im Lande, aber die lokalen Staatsorgane wollen oder können diese Bewegung nicht meistern. In Wahrheit sind die untergeordneten Beamten und Polizeiorgane sehr oft Anhänger der Nationaldemokratie und sympathisieren mit der Judenhetze."101

Der Antisemitismus wurde somit zur Schlüsselfrage für die jüdische Existenz in Mittel- und Osteuropa in den dreißiger Jahren. Die verschiedenen Äußerungen des Antisemitismus zu verfolgen, spielte eine zentrale Rolle im Denken und Handeln der jüdischen Öffentlichkeit. Dan Diner vertritt die These, das Verständnis des Antisemitismus sei bei Juden in Europa während der Zeit zwischen den Weltkriegen von klassischen Antisemitismusmodellen in Staaten mit ethnisch heterogener Bevölkerung, wie Polen, Rumänien und Ungarn, beeinflußt gewesen ${ }^{102}$. Diner geht davon aus, daß europäische Juden (mit Ausnahme der deutschen Juden) den deutschen Antisemitismus als Teil des im Grunde religiösen und in der Folge nationalen Antisemitismus interpretierten, der wie in den Ländern Osteuropas üblich seinen Ausdruck in Pogromen fand. Daher hätten sie die neuartigen und vom üblichen Muster abweichenden Elemente dieses Antisemitismus nicht erkennen können. Wie deutsche Juden den nationalsozialistischen Antisemitismus verstanden, ist nur schwer einzuschätzen: Sie konnten sich infolge der von der Zensur verhängten Einschränkungen und den fehlenden für eine entsprechende Diskussion notwendigen demokratischen Rahmenbedingungen kaum öffentlich mit dem deutschen Anti-

$99 \mathrm{JR}$, Die Erklärung des Innenministers, Nr. 17, 28. 2. 1936.

100 Jüdisches Gemeindeblatt Danzig, Die Lage der Juden in Polen 1936, Nr. 10, 1. 2. 1936.

$101 \mathrm{JR}$, Der Pogrom in Przytyk, Nr. 22, 17. 3. 1936.

102 Diner, Auswanderung ohne Einwanderung, S. 148. 
semitismus auseinandersetzen; für sie stand daher die Beschäftigung mit den antisemitischen Ausfällen in Osteuropa im Vordergrund, die ihnen als Analogie zur Erörterung ihrer eigenen Situation dienten. Hiervon unterschied sich die Situation der Juden in anderen Ländern erheblich. Die polnischen Juden waren frei von den Zwängen, die die deutschen Juden einschränkten. Die von ihnen geführte Diskussion war offen, ihre Standpunkte waren bisweilen kämpferisch. Sie verwiesen auf die zentrale Rolle Deutschlands bei der Verbreitung antisemitischen Gedankenguts und verstanden den Kampf gegen diese Ideen als einen Kampf von symbolischer und politischer Bedeutung für die "Judenfrage" insgesamt.

Prinzipiell und theoretisch, nicht praktisch, hatte sich am Schicksal polnischer Juden bis zu jenem Zeitpunkt nichts geändert. Sie genossen weiterhin formale Gleichberechtigung und alle bürgerlichen Rechte, besaßen ihre politische Tradition, die in der weitverzweigten organisatorischen und parteipolitischen Tätigkeit zum Ausdruck kam. Außerdem verstanden sie sich selbst als eine nationale Minderheit, die ihre Rechte schützen mußte und die in den Regierungsinstitutionen vertreten war. Darüber hinaus wurden sie, wenn auch in eingeschränktem Maße, durch politische Kräfte im allgemeinen politischen und gesellschaftlichen System Polens unterstützt ${ }^{103}$. In vielerlei Hinsicht gab es Entsprechungen zwischen der polnisch-jüdischen Reaktion in den dreißiger Jahren und dem Kampf deutscher Juden gegen den Antisemitismus in der ausgehenden Weimarer Zeit. Bei garantierter Gleichberechtigung vor dem Gesetz und vollen politischen Rechten hatten auch deutsche Juden am Ende der Weimarer Republik einen Kampf um die öffentliche Meinung geführt und von ihrem Wahlrecht entsprechend Gebrauch gemacht. Wie die deutschen Juden, die ihre politische Unterstützung den Liberalen entzogen und auf die Sozialisten übertragen hatten, so verließen polnische Juden das Lager der Sanacja und gingen zu den Sozialdemokraten über ${ }^{104}$. Sie suchten politische Partner im Parlament, mobilisierten die Intellektuellen, versuchten die jüdischen Wähler zu beeinflussen und führten weitreichende Aufklärungskampagnen durch. Das deutsche Judentum wurde dann Anfang 1933 aller politischen Rechte beraubt. Die legalen Kampfmittel, die ihm zur Verfügung gestanden hatten, waren damit auf ein Minimum beschränkt. In mancherlei Hinsicht unterschieden sich die politischen Traditionen der Juden in Deutschland und Polen grundsätzlich. So hatten deutsche Juden niemals den Status einer nationalen Minderheit besessen und waren niemals dazu gezwungen gewesen, die gesetzlichen Mittel im Kampf um ihre Gleichberechtigung zu überschreiten. Da sie also die Tradition des Kampfes nicht kannten und die Bedingungen für einen Untergrundkampf fehlten, konzentrierten deutsche Juden ihre Kräfte auf die Verbesserung ihrer Lebensbedingungen bei stetig zunehmender Diskriminierung und Demütigung.

Ende 1936 hielt ein Europabesucher aus Palästina seine Eindrücke vom Kontinent in seinem Tagebuch fest:

103 Korzec, Antisemitism, S. 98 ff. - Die Unterstützung der polnischen Juden durch die sozialisitsche Partei Polens PPS war für den Unterschied zwischen der Situation polnischer und ungarischer Juden entscheidend. In Ungarn wurden Juden allgemein nur von einer kleinen, mutigen Gruppe von Intellektuellen unterstützt; Mendelsohn, East Central Europe, S. 72.

104 Melzer, No way out, S. 98 f., $108 \mathrm{f} ., 153$. 
„Das Gefühl der quälenden Last, insbesondere für jemanden, der von außerhalb hierher [nach Deutschland - Y.W.] kommt, kann kaum beschrieben werden. Als ich in Lemberg war, hat man Juden vor meinen Augen auf offener Straße geschlagen. Am Tage, als ich in Bialystok eintraf, kam es zu Pogromen in Wysokie Mazowiezkie, und trotzdem kann man die Atmosphäre in Polen nicht mit dem Gefühl der bis auf den Grunde demütigenden Hilflosigkeit und Beleidigungen vergleichen, das der Jude [in Deutschland] erfährt, und zu dem besonderen ,jüdischen Gefühl gesellt sich noch die allgemeine Atmosphäre der Kriegsvorbereitung: Fast jeder Dritte auf der Straße trägt Uniform ..."105

Mit diesen Worten traf der Besucher einen der wesentlichsten Unterschiede der Situation deutscher und polnischer Juden: Polnische Juden verteidigten sich, wenn auch nicht immer erfolgreich, gegen den Antisemitimus, deutsche Juden nicht. Um diese Unterschiede zu erkennen, bedurfte es allerdings keines externen Beobachters. So publizierte Sneh Ende 1937 einen Aufsatz, der die Bedingungen des Kampfes in Polen und Deutschland miteinander verglich ${ }^{106}$. In dieser verspäteten Reaktion auf Roberts Weltschs Artikel „Tragt ihn mit Stolz, den gelben Fleck“ meinte Sneh, polnische Juden beabsichtigten nicht, sich mit „einer Verbesserung und Verschönerung des aufgezwungenen Ghettolebens" zu begnügen. Er zeigte zwar Verständnis dafür, daß angesichts der totalen Verhältnisse unter dem NS-Regime deutschen Juden keine andere Wahl bliebe. Die polnische Gesellschaft befinde sich jedoch noch immer im Kampf um „das Image der Republik, um das System des Staates, um die Grundlinien der Außen- und Innenpolitik". Unter diesen Umständen sei es wichtig, so Sneh, alle Möglichkeiten des legalen Kampfes auszuschöpfen, auch wenn sie noch so beschränkt seien.

Ein weiterer Aspekt des Kampfes, der deutsche von polnischen Juden unterschied, war die physische Abwehr. Gewalt war zunächst ein sekundäres Phänomen im nationalsozialistischen Deutschland. Wenn es spontane Übergriffe gab, so wurde ihnen noch 1933 ein Ende gesetzt, nachdem sich das neue Regime etabliert und organisiert hatte. In Polen gab es eine lange Tradition physischer Gewalt gegen Juden, deren Wurzeln bis zu den Pogromen unter dem zaristischen Regime zurückreichten. Der polnische Antisemitismus hatte darüber hinaus einen stark volkstümlichen Zug, und gewalttätige Ausschreitungen begleiteten den Alltag in Polen in den dreiBiger Jahren, eine Tendenz, die nach 1935 deutlich stärker wurde. Unter diesen Umständen überrascht es nicht, daß polnische Juden sich gegen derartige Übergriffe zur Wehr setzten ${ }^{107}$. Der Bund hatte als erster infolge der gewaltsamen Zusammenstöße mit den Regierungsbehörden in Wilna 1902 begonnen, Selbstverteidigung zu üben. Er hielt am Prinzip der Verteidigung aufgrund der Ausschreitungen nach der Gründung eines unabhängigen Polens fest und war somit bestens geeignet, angesichts der wachsenden Gewalt in den dreißiger Jahren entsprechendes Verhalten durchzusetzen ${ }^{108}$. Der Bund unterstützte den Kampf jüdischer Studenten in den Hochschulen Polens. Zum Teil führten die Studenten diesen Kampf selbständig, indem sie sich gegen Angriffe in den Universitäten und gegen die separaten Sitzbänke für jüdische

105 LI, Akte III-38-43-12, Deutschland-Tagebuch, Berlin 18. 10. 1936, 1.

106 Haynt, Wir weisen den gelben Fleck zurück! (jidd.), 17.10. 1937, bei: Sneh, Writings (Anm. 28), S. 251-253.

107 Rowe, Jewish Self-Defence.

108 Ebenda, S. $108 \mathrm{f}$. 
Studenten wehrten ${ }^{109}$. Der Abwehrkampf wurde auf verschiedenen Ebenen gleichzeitig geführt, bei den Debatten des Sejm und durch die Mobilisierung der polnischen Intellektuellen. Der Widerstand und die physische Abwehr der jüdischen Studenten an den Universitäten und der Mitglieder des Bundes an den Toren der Hochschulinstititute waren dabei eines der wichtigsten Elemente in den Auseinandersetzungen. Die gewünschten Ergebnisse traten jedoch nicht ein. Die absolute Zahl jüdischer Studenten ging zurück. Doch schon allein der Kampf an sich wies auf die unterschiedlichen Bedingungen und politischen Reaktionen in Deutschland und Polen hin. In Deutschland wurden Juden aufgrund eines staatlichen Gesetzes aus den Universitäten verdrängt, während in Polen die entsprechende Initiative spontan von den rechten Parteien ausging. Deutsche Juden konnten keinen Kampf gegen ihre Isolation an den Universitäten oder gegen die Gesetzgebung führen, die ihren Anteil an den Universitäten und anderen Hochschulinstitutionen verminderte. Für deutsche Juden erschöpfte sich der Kampf um die Hochschulbildung in der Etablierung eines jüdischen Erziehungssystems in Deutschland und in den Bemühungen um die Emigration der Jugendlichen.

Auch der Kampf gegen den Boykott jüdischer Geschäfte hatte in Deutschland einen anderen Charakter als in Polen. Die polnische Rechte ebenso wie die Mitglieder der NSDAP in Deutschland agierten aufgrund wirtschaftlichen Neides und verbreiteten Konkurrenzdenkens, um jüdische Händler von den Märkten zu verdrängen. In Deutschland handelte es sich bei diesen Händlern mehrheitlich um ausländische Juden. Neben der nicht sehr weitreichenden Tätigkeit des Central Vereins, der sich im wesentlichen auf die juristische Beratung der Betroffenen beschränkte, wurde der Kampf hauptsächlich von den ausländischen - insbesondere den polnischen Konsulaten geführt, die den wirtschaftlichen Status ihrer Staatsangehörigen in Deutschland wahren und damit deren Rückkehr in das Herkunftsland verhindern wollten ${ }^{110}$. In Polen führte der Bund einen aktiven Kampf unter Waffeneinsatz und Selbstverteidigung, zum Schutze der Händler auf den Märkten und der gesamten bedrohten jüdischen Öffentlichkeit. Der Bund schützte jüdische Geschäftsbesitzer vor dem Druck des Wirtschaftsboykotts, während in Deutschland Juden vor den Schäden des Boykotts resignieren mußten ${ }^{111}$. Der Bund schützte jüdische Frauen und Kinder in den öffentlichen Parkanlagen, während Juden in Deutschland angesichts der „Parkbänke“ für Juden und dem Verbot, sich an für Deutsche reservierten Erholungsstätten aufzuhalten, hilflos blieben ${ }^{112}$. Im Laufe der dreißiger Jahre wurden sich polnische Juden der Gefahr bewußt, die ihnen durch die aus Deutschland nach Polen importierte antisemitische Gesetzgebung drohte. In ihrem Kampf gegen diese Einflüsse wußten sie ihre formalen Rechte, wie die Beteiligung an Wahlen und die Vertretung im Parlament, ebenso zu nutzen wie die öffentliche Meinung. Sie führten einen aktiven Kampf und wiesen auch die körperliche Selbstverteidigung und den bewaffneten Kampf nicht zurück. Dieses Verhalten entsprach den Lebensbedingungen in Polen, solange die offizielle Position der Regierung das jüdische Leben in Polen stützte und trug. Ob diese Methoden auch eine sinnvolle Reaktion auf

${ }^{109}$ Melzer, No Way out, S. 74, 76, 79 ; Rowe, Jewish Self-Defence, S. $120 \mathrm{f}$.

110 Weiss, Ostjuden, S. $215 \mathrm{f}$.

111 Rowe, Jewish Self-Defence, S. $117 \mathrm{ff}$.

112 Ebenda, S. 121. 
die Lage der Juden darstellten, nachdem die polnische Regierung ihr Interesse an der Bewahrung des jüdischen Status verloren hatte, muß angezweifelt werden. Noch stärkere Zweifel aber ergeben sich hinsichtlich der Frage, ob ein solches Verhalten die Not der deutschen Juden verringert hätte. 